\begin{tabular}{ll}
\hline \hline MINING AND METALLURGY INSTITUTE BOR & ISSN: 2334-8836 (Štampano izdanje) \\
UDK: 622 & ISSN: 2406-1395 (Online) \\
\hline \hline
\end{tabular}

Gordana Rendulić, Marija Miric ${ }^{* *}$

\title{
THE ROLE OF LEADERS IN MOTIVATION OF EMPLOYEES IN THE MINING COMPANIES
}

\begin{abstract}
The new millennium brings a new paradigm of business that takes place in completely different conditions and is based primarily on knowledge, creativity and post-modern leadership. Radical changes, in which today's economy and its entities exist and develop, require the new ways of leadership. Hence, the new paradigm articulates and gives a critical dimension of leadership, as an interaction between the leaders and followers, with the intention to change it, based more on the emotional and ethical assumptions than on forced active influence, having in mind the nature of the business performed by the employees in various activities, especially in the mining companies. The aim of this analysis is to determine the correctness of relationship between the leaders and followers as a social category and projections of further trend of this relationship, given that it is supposed that this relationship is A direct reflection on motivation the followers in their work and the results of work in the mining companies.

Keywords: corporate culture, leadership, motivation, mining companies, leadership style, performance, business success
\end{abstract}

\section{INTRODUCTION}

Today's business is increasingly leaving the intensive model of economic growth based on the comparative advantages of natural resources and unskilled labor. There is a new form of economic creativity which increasingly inaugurates some new intangible origin resources such as: knowledge, creativity, innovation, information, quality, standards, time, design, speed, know-how and other. The level of business success depends on the quality of human resources and their competence available to the business systems; regardless of their place in the organizational structure. A new knowledge about business and people is a source for completely new business philosophy, the initiator of the new changes and bearer of risk, the creator of innovation and resource allocation, the designer of new quality and

values, the creator of business performance and others. On the social scene the civilization appeared whose base is on education and development system, which requires that every person works in a scientific manner in order to actively participate in the social and economic reality, creating a socially and personal wealth.

Modern economy functions in a completely new environment and a new geo culture that, in addition to the knowledge and standards in economic terms, respects and develops a knowledge for the new ethical norms and forms of corporate culture that significantly change and impact on the leadership, business policy, employee behavior, and most of all life and work of a modern businessman in the mining companies. The absence of leadership development

\footnotetext{
*University of Kragujevac, Faculty of Technical Sciences Čačak, e-mail:gordana.rendulic@ftn.kg.ac.rs

*** Student of Entrepreneurial management at the Faculty of Technical Sciences Čačak
} 
in the contemporary business, based on a strategic approach, would cause a huge damage to all business systems and overall economic and business creation, especially in developing countries that are in the process of transition of ownership, as is the case in the Republic of Serbia. Poor leadership is a key factor in the failure of business and the main obstacle to overcome economic recession. Therefore, the role of the leadership in mining companies due to the nature of business and the risks to which the employees are exposed, becomes an essential activity of the management of each company.

\section{LEADERSHIP AND ENVIRONMENTAL CHANGES}

Changes and their permanent metamorphosis do not only condition the economic life of a society, but they have become a way of life of economic entities in every developed economy. Business systems are in a state of stability when the strategy, organizational structure and style of their leadership are in accordance with the internal and external environment. But the state of stability of business systems is difficult to maintain because it is permanently disturbed by the changes in the internal and external environment. Globalization as a planetary process of change has brought many demands to the companies to be successful in their further work. One of the important requirements is that the enterprises should increase their ability and readiness to learn, to develop their human resources in order to overcome successfully the complexity and increasing uncertainty in which they carry out their mission.

"Globalization of knowledge can be understood as the growth, development and knowledge exchange between different economic entities on a global basis." [1] That is why the changes in the structure and leadership of the company are inevitable, which means that the leadership is forced to live with changes and to adapt and transform its role in line with the nature of the environment. Changes in the companies in our country are a direct response to the transitional changes in property, changes in the market (desire of customers, changes in competition), changes in state and legal regulations, changes in the economic situation, changes in the political atmosphere, changes in the international relations, and more. Changes and knowledge are the main bearer of development, and the main cause of decay, where development and change are completely natural processes, the causal consequence of survival and universal rules of existence.

This general principle of change management also applies to mining companies which activity is based on the new knowledge, technologies, new methods, as well as new ways of management and processes and employees, no matter how specific they are. And the mining production is increasingly based on the new knowledge and capabilities of human resources. "In the knowledge economy, knowledge takes on some specifics and becomes the focus of interest in the economic science and practice. It now becomes the organizational knowledge at the level of the business system and increasingly becomes the essence and carrier of business development and growth, and the structure for the creation of new knowledge. "[2]

Changes are the way of life of today's companies and management in them and the means in hands of leaders. The leadership itself is a consequence and cause of resulting and incorporated changes in the business systems. Some of the definitions of change are: "Change within any element of an organizational system that promotes functionality, that is at a higher level of consistency for the environmental requirements," "modification of task, structure, technology or 
people in an organization", "planned action that represents an attempt to systematically redesign the organization in a way that will allow it to adapt to the significant changes in the external environment and to achieve the new goals, "“" abandoning the old way of doing things and accepting a new one that will contribute better results." [3]

The management of the company should recognize the environmental factors, determine the character and intensity of their effect and interact in order to create an economic horizon to the guide business, i.e. to determine the goals and strategy of the company. The idea of a management change is to enable companies to retain and improve their positions in the new circumstances. Therefore, a management change is a systematic and structured approach in creating a sustainable change in employee behavior within a company. Today's intensity and pace of change has changed the way of business management, putting leadership as an integral part of management in a very important place giving it a great role and importance in the management system.

\section{LEADER'S ABILITY AND BEHAVIOR}

Leadership as an unstoppable metamorphosis process continues its evolution in the modern economy. Leadership evolution starts from the connection of the leader and subordinate followers through a hierarchically - composed chain of command and oneway communication process to position the leader through the possession of the right answers and reactions, which directly qualifies him/her for leadership and as an unbiased attitude of influence between the leaders and followers. Leadership can be treated as a collective process that includes the leaders and followers and is formed in a specific social and historical context.
"Therefore it is necessary to make a principle distinction between the management and leadership: while the management is focused on personal problems and problems of human resources, organizational setup and structure, preparation of certain funds and their executive recruitment, efficiency and utilitarianism, that is the internal organizational issues, management, technical objectives and control, the leadership is focused on the vision, construction of a "big picture" of change, innovation, strategic landmarks, purpose or purposes of the future.'[4] Leadership in its analysis has two points of view: conventional perspective based on the concept of efficiency, since it starts from the assumption that the leadership takes place in a rational created institutions, where the fundamental function of the leadership is a mobilization of followers in a direction of organizational objectives and critical perspective involving various sociological concepts including the social structure, processes, culture and norms oriented towards the discovery of ways in which power, control, and legitimacy conflicts affect the dynamics of relations between the leaders and followers".[5]

Increasingly the question is what is a leadership? And who are the leaders? Leadership is a process of influencing and directing the activities of members of organizations towards achieving the business objectivities. It is a wise way how a leadership uses its influence and power. Leadership as the process of forming the behavior of people in the business system is focused on a human interaction "influencing the others" and on an internal integration of business system. [6] Leadership is demonstrated when the individuals mobilize institutional, political, psychological and other resources to arouse, engage and satisfy the motives of followers. [7] From the above, it can be seen that a leader is a chosen as a favorite person 
with a central role and the highest social status and the spirit in front of everyone in the business system. This is a man with a physical and personal qualities and characteristics (age, appearance, communication skills, knowledge, intelligence, creativity, integrity, flexibility, and an aspiration for leadership, reliability, self-confidence, extraversion, emotional stability, and the like). According to the global leadership prognosis, a leader is defined as someone who mana-ges the performance and responsibilities of other individuals in the organization. [8]

Integrity and morality (ethical and spiritual leadership) of leaders increasingly take the key positions in the profiles of leaders, so creating both the basis and guarantee for respect from followers, and all this leads to the business success. [9] Altruism or concern for others and integrity are also the important similarities. As for the differences the authentic leaders emphasize authenticity and self-awareness and tend to be more transactional than the other aspects of leaders do. Ethical leaders emphasize the moral problems while spiritual leaders emphasize vision, hope and faith, as well as work as a profession.

\section{SOCIAL DIMENSION OF LEADERSHIP}

Leadership is not what management is, even though it has a strong relationship with management and makes it an integral part. In most business systems there are too much of management and too little of leadership. The manager, no matter how good is a planner, organizer, coordinator and process controller, without the motivational abilities of the leader cannot lead to good business results. The leader is successful if know how to stimulate and rally the commitment of his/her followers to the business system and all his/her activities, even without managerial skills.
The manager is successful in doing business if has the leadership capabilities. A leader is the one who is able to influence the attitudes, opinions, decisions and actions of each follower.

Leadership is a specific type of relationship in management and is based on a social activity or activity between the leaders and followers. Leadership is focused on a human interaction "impact on others" and on achieving the business results. Leadership as a process in itself requires "real" and capable leader who creates a vision and responsible followers who accept the vision and follow the ideas and values of leader. Fair and humane attitude of these parties in the process has a direct impact on performance the business system which is the essence of leadership to make all followers gather around one idea and so direct the creative energy, knowledge and ability towards achieving a defined objective. Followers as bearers of working activities and supporters' of common ideas for achieving organizational goals are also individuals with their personality, with their own personal profile and their characteristics. Leaders should always have this fact in mind when it comes to perceive the behavior of individuals at work, decision making, communication, control and others.

For modern leader and leader of the future, it is not enough to have a high level of IQ, but the so-called emotional intelligence; EQ is needed and it is ability to be more sympathetic to the others, to cooperate, to properly assess, to create a good relationship, to be attractive and ot-hers [10]. Emotional intelligence indicates the importance of ability of leaders to express their feelings to employees, to live in harmony with them and to use them to achieve the important organizational goals. Personality is, in addition to traits, abilities and personality traits as the holder of differences in behavior and work, conditioned by a number of 
other dimensions and complex phenomenon, which is an area of psychological research. Kno-wing the personality of the individual should be the first item when entering the world of work, because the personality of individuals creates the profile of business system. There are different people and different behaviors of these people in the business system. Some of them are consistently friendly, calm, and quiet, others are aggressive, rude, talkative, nervous, etc. While some are effective in decisionmaking and risk-taking, creative and open to the new ideas, have high moral standards, others may be hesitant, timid, slow, passive, without ideas, flexible in their moral attitudes, etc. It is obvious that a person makes a unique system of proper behavior, which an individual differs from others in the business system. For business system management, it is very important to understand the personality of individuals, because on the basis of that the future reactions of employee-followers can be predicted in a certain situation and it could be reacted to them adequately. Personality is a very layered, complex and developmental psychological phenomenon; it is a conditioned category by numerous factors: biological, sociological and situational. "The psychology of parents and educators is decisive in the process of growth and development the individual" [11]

To comply with the individual profile and nature of the work, the selection of psychologists should be detailed in the personality profiling of the candidates for the purpose of their efficient performance. Profile of employee with details would be available (in the form of psychological, physical, intellectual and professional files) only for responsible people in the sector of Human Resources. That file would contain information on an individual development from the childhood (family structure, growing up with or without their parents, their emotional development, strictness of parents, profession of parents, financial status, family status in the environment, etc.), schools that an individual attended, the jobs done, the qualification gained, marital status and others. All data on an individual would serve to leader to fully understand their followers, their behavior, their attitude towards work, towards colleagues and towards authority, their responsibility and others and to build attitude towards them and to consequently treat them. Harmonizing the relationship of the leaders and followers is essential for the life and development the business system to motivate the followers and good performance in work.

\section{LEADERSHIP AND MOTIVATION}

Leadership implements its evolution development and metamorphosis through a prism of motivation system the followers. Leadership is directly related to the inspiration of followers and management of their behavior in the performance of certain tasks. The attitude of leaders towards the followers expresses leadership style in a certain time and certain situation. The key criteria for distinguishing between the leadership styles are: the leaders attitude to the followers motivation (coercion or incentives), the way in which the leader makes decisions, source of power that is used to influence on followers, leader flexibility to adapt to different situations, characteristics of leaders (mental and physical, moral, professional, etc.), characteristics of followers and others. According to these criteria, there is a whole range of leadership styles from classic to the modern styles.

In an effort to identify the factors that most affect the business success of the company, the contemporary authors are increasingly emphasizing the employee motivation as one of the key determinants of performance. Today, motivation is in the focus of 
the interest of a modern leader, who has an active and important role in encouraging his/her followers for greater engagement at work and greater efficiency and effectiveness in business "Efficiency is thus focused on the choice of needs that the company will satisfy, i.e. the choice of goals and activities to provide it, and the efficiency on the production capacity and rationality of using the resources that the company has at its disposal." [12]

The quality of the accomplished performance of members of the organization is directly conditioned by a degree of their motivation, among other things, by an ability of the leader to encourage his/her followers in the right way. Motivation is a set of processes that support, direct and maintain the behavior of people, aimed at achieving a particular goal. It is considered as a complex psychological category that dictates a significant part of behavior of employees in the company, and is the basic catalyst for business actions. Directing the behavior of employees in the company, so that it is desirable and acceptable for its operation and business policy, is the responsibility of the leader.

The notion of leadership is complex, multidimensional and multidimensional, and its definitions differ depending on the aspect from which different authors view and determine it. One of the most comprehensive definition of leadership was given by Peter Northouse, who under the leadership implies a process in which an individual exercises influence on a group, in order to achieve a common goal. Therefore, it is a complex, dynamic process that is realized in the context of a group and basically implies an interactive relationship between the leaders and followers, whose interaction is more pronounced in the modern business conditions. Namely, the modern companies organize their business based on a team work, where leadership takes on a completely new dimension, reducing the formal role of leaders in such environment. Leadership is a central function of management and refers to directing the work activities of employees in the organization, as the strategic most important way to achieve the organizational goals. Managing people, among other things, means to know how to motivate them, thus ensuring that they are doing their job well and contributing to achieving the mission and achieving the goals of the business system.

An important aspect of leadership in the role of employee motivation is the ability of the leader to identify the individual goals of each employee, and accordingly offer them an adequate reward for successfully accomplished tasks, thus ensuring compliance of individual and projected goals of the organization. The ability to recognize the motive of employees and the satisfaction of their needs is what separates successful from unsucessful leaders. If motives of an employee are known, the leader is able to anticipate his/her future behavior and accordingly direct him/her to the right path to achieve a higher level of productivity and better financial results of the business system. The effects of employee motivation by the leaders are different in a different company, which is again conditioned by the activity in which the work process takes place both by the structure of the employees themselves and the conditions in which the work activities are carried out. "The current business can be organized successfully or less successfully, which will directly affect the final business result-income. Concrete producers, mining companies have different natural and technical business conditions as well as different environmental impacts in relation to the average producer of this group, a group of workers. The occurrence of these differences results in a profit deviation of a particular mining company in relation to the profit of the average 
producer. This impact cannot be changed during the reproduction process, and not by the organizational efforts of workers and managers. "[13]

How a leader will motivate the followers in such companies depends first of all on the style of leadership applied. At the same time, the leadership style is conditioned by a set of factors, in which the organizational structure, organizational culture, as well as the personality and characteristics of the leader are distinguished. There are numerous criteria and ways of classifying the leadership styles. Historically, the leadership style goes from a commanding, autocratic to participatory, team leadership. Thus, the leader of the autocrats as the basic means of shaping and directing the behavior of employees will use coercion, punishment and strong control, with a high degree of rigidity and directives, while the leader of the democratic participatory style will motivate his/her followers giving a greater authority and responsibility, giving them the opportunity to participate in making the important decisions. Experience and practice show that a greater degree of humanization the relationship between the leaders and followers give better employee motivation results. Each style of leadership brought a certain style of incentive-motivation of its followers. The attitude of leaders and followers evolved increasingly in favor of the followers. Leaders, thanks to their abilities and superior qualities, developed the specific relationships with followers, and thus inspired them in the most difficult moments in the business system, and thus strongly motivated them to often overcome their own possibilities and expectations. Capable leaders are very creative with many ideas and easily create the climate of change and climate of business as an important incentive factor. "Climate is an emotional value reflection of the organization culture. It is conditioned by the most common way of decision-making, the way of management the system of distribution of salaries, human resources management policy. The climate consists of relatively permanent, emotional, social relations and interpersonal relations of the organization members, as well as the influence of these attitudes on the behavior of employees. "[14] Followers in this business atmosphere are emotionally and unconditionally tied to the mission of a capable leader and are often identified with it.

Today, it is mentioned more and more the visionary leadership, as the ability to create systems, to make the vision a reality, despite a turbulently changing environment. Visionary leadership is less concerned with the interaction between the leaders and followers, which is in the focus of numerous leadership models, and more by an interaction between the leaders and groups or leaders and systems.[15]

The idea that different people will have different motives is of vital importance to the leaders in deciding on the system of rewarding and motivating employees. Each individual represents a unique set of personal characteristics, aspirations and motives. Therefore, individualized approach of leaders to each employee is necessary, in order to identify their needs and desires and to provide opportunities for their satisfaction. In order to achieve this, the leader must have a good knowledge of his followers, and apply different methods and techniques of motivation. High cohesiveness of the group or team is necessary because it is the basis for discovering their motives. A leader who does not know his/her followers well enough cannot expect their loyalty and trust.

It is unjustified to believe that the basic motives for the work of employees are money and other material rewards. In the modern business conditions, characterized by dynamism, turbulence and stochasticity, the top-level needs, such as the needs for achievement, development and self- 
actualization, come to the place of material rewards as the basic motives for work. Here, the key role and significance of the leaders are seen, whose task is to convey their vision and optimism to the employees, and convince them that success is possible, all in a function of creating greater prosperity for the business system itself.

Modern leadership, and especially transformational leadership, is linked to the changes, which are the main feature of modern business. Under conditions of uncertainty, resistance to change is inevitable, and the leader is to manage it. In this sense, motivation and rewarding are the most powerful weapon in the hands of leaders, which can be used to eliminate the resistance and create an organizational climate that supports the implementation of changes in an organization.

The motivation system itself, in addition to being stimulative, can sometimes be disincentive to the followers. This case refers to rewarding the follower. Since the prize is a very sensitive category, it should be in the focus of management of the business system in order to achieve a real stimulus effect. In order for a prize (in any form) to be stimulated, it should be fair and awarded, in the same treatment, the same reward for the same results. The reward as a stimulating part for a better and more efficient performance of jobs is important every-where where the organized work is carried out, and especially the place in mining operations where the nature of the work is specific, in view of the working conditions, the difficulty in carrying out work opera-tions, the risk at which works are performed and etc.

Finally, in order to effectively and efficiently motivate employees and thus fulfill one of their most important tasks, the leader must be adequately motivated. Selfmotivation is a feature inherent to the leaders, as it is question of people of the inter nal control locus. In addition, the leader must be an excellent connoisseur of psychology, sociology and organizational behavior, in order to be able to create a favorable organizational climate for the work of employees and to ensure healthy and human interpersonal relationships in a long period. The basis for employee motivation is the correct and clear communication between the leaders and followers that must be based on mutual respect and trust. The success of the leader is measured by his/her ability to motivate employees based on proper communication, and it is important that the leader listens to his/her environment and thus gets the valuable information about his/her team members.

The growing tendency of the importance of human resources to achieve the business, economic and overall social development in the knowledge economy points to motivation as the most effective means of achieving the goals. The role of leadership in motivating employees in the business system is of immense importance and today is one of the main determinants of business success.

\section{CONCLUSION}

Many external and internal factors are related to the success of company. The role of leaders in a strategic approach to the management is inviolable and essential. The leadership role in a turbulent environment is to project an organizational and functional entity in the mining companies. In order for success to be adequate, the leaders need to optimally harmonize their own behavior with the requirements of the environment from one and the inner environment, with the emphasis on the needs of the followers, on the other side. Due to the long transition period and the general crisis that has ruled our country for a long period of time, numerous problems have been noted in both 
business and leadership. Leaders in the Serbian mining companies use the democratic leadership style to the fully extent. They are dedicated to work and goals and are very motivated in their work. The special characteristics that the followers rate in the leaders are: knowledge, abilities, creativity, charisma, honesty and politeness. In the opinion of the followers, the leaders in this region do not possess a sufficient level of emotional intelligence, tolerance and flexibility. The style of leadership applied in the Serbian companies varies depending on the activity, the size of the business system, the emplo-yee structure but the demands of the followers are absolutely identical. The followers require from leader even greater responsibility, open communication, respect, respect for employee suggestions and a friendly attitude. In order to be accepted by the followers and at the same time to be their heroes, in addition to the vision, technical and conceptual knowledge, the leaders need to give more attention to the followers. Leaders should be ready to listen to suggestions, proposals and followers' ideas, to express openly their opinions, praise good ideas, argumentatively rejecting a bad idea, interpreting the current state of the environment and explaining the goals of the work. Only an open and rightful relationship with the followers, clear goals and authority, based on knowledge and integrity, can make the leaders successful.

\section{REFERENCES}

[1] Radovanović V., Savić Lj.: Knowledge and Innovations - Key Factors of Development and Employment in Mining Companies; Mining and Metallurgy Engineering, Bor, No. 1/2014, p. 162. DOI: 10.5937 MMEB1401153R, ISSN 2334-8836.

[2] Carr D., Hard K., Trahant, W.: Managing the Change Process T. Zaltman
G., Psychologists for Managers, Stoner J., Freeman R., Management, 2006.

[3] Kottler, J. P.: "What Do Leaders Really Do." Y Gabarro, J.J. Managing People and Organization, Harvard Business School Publications, Boston, 1992, p. 103; and Iles, P. and Prece, D. "Developing Leaders, or Developing Leadership?" The Academy of Chief Executives Programs in the North East of England "Leadership, 2006, p. 319.

[4] Rost, J C. Leadership for the TwentyFirst Century, op. cit. p.149; and Nahavandi, A. The Art and Science of Leadership Prentice Hall, Upper Saddle River, 2008, p. 10.

[5] Rots, J.C. Leadership for the TwentyFirst Century, op. cit, p.17.

[6] Stogdill, R. "Personal Factors Associated with Leadership: A Survey of Literature," The Journal of Physiology, 25, 1948, pp. 35-71.

[7] Howard, Ann; Wellins, Richard S. (2008-2009) Global Leadership Forecast, DDI Center for Applied Behavioral Research, USA, p. 7. Text available at: http:

//www.ddiworld.com.2011

[8] Burns, J. Transforming Leadership: A New Pursuit of Happiness. Grove Press, New York, 2003, p.16, 231 (D. Goleman 2012).

[9] Goleman Daniel. (2010) Leadership That Gets Results. Text available at: http://hbr.org/ 2000/03/leadership-thatgets-results/ar/2012.

[10] Carl Gustav Jung: "The Development of Personality", Academic Book, Belgrade, 2008 (in Serbian)

[11] Savić, Lj., Radovanović, V.: Business Success Management, Mining and Metallurgy Engineering Journal, No. 2/2015, Bor, p. 162 DOI: 10.5937 MMEB1502161S, ISSN 2406-1395. 
[12] Savić, Lj., Radovanović, V.: Influence of Management Measures on Profit in the Mining Companies, Rudarski radovi, No. 1/2013. Bor, p. 176 (in Serbian) DOI: $10.5937 /$ rudrad 13011 75S, Udk: 330.1; $061.5(045)=861$

[13] Radovanović, V.: Business Ethics and Corporate Culture, Tehnika - Mana- gement, number 4/2011. Belgrade, p. 653 UDC: 174.4.026.2 (497.11), ISSN 0040-2176

[14] Nanus B.: "Visionary Leadership" and "The Manager's Bookshelf", Fourth Edition, by Pierce L.J. and J. and J.W. Newstron, Collins Cole Publishers, New York, 1996. 